\title{
Mushroom fruiting body yield and morphological characteristics from different strains of Pleurotus eryngii
}

\author{
Iryna Bandura $^{1}$ (D), Omoanghe S. Isikhuemhen ${ }^{2 *}$ (D), Alina Kulik ${ }^{1}$ (D), Nina Bisko ${ }^{3}$ (D), Maryna Serduik ${ }^{1}$ (D), Volodymyr \\ Khareba $^{4}$ (D), Olena Khareba ${ }^{4}$ (D), Iryna Ivanova ${ }^{1}$ (D), Olesya Priss ${ }^{1}$ (D), Oleksandr Tsyz ${ }^{4}$ (D), Serhii Makohon ${ }^{1}$ (D), Serhii \\ Chausov $^{1}$ \\ ${ }^{1}$ Department of Food Technology and Hotel- Restaurant Business, Tavria State Agrotechnological University, Melitopol, Ukraine. \\ ${ }^{2}$ Mushroom Biology \& Fungal Biotechnology Laboratory, North Carolina A\&T State University, Greensboro, NC. \\ ${ }^{3}$ M.G. Kholodny Institute of Botany, National Academy of Sciences of Ukraine, Kyiv, Ukraine. \\ ${ }^{4}$ Department of Vegetable Cultivation, National University of Life and Environmental Sciences of Ukraine, Kyiv, Ukraine.
}

\section{ARTICLE INFO \\ Article history: \\ Received on: April 10, 2021 \\ Accepted on: August 03, 2021 \\ Available online: January 07, 2022}

\section{Key words:}

Biological efficiency,

morphological characteristics,

mushroom cultivation, strain

genetic background

\begin{abstract}
Pleurotus eryngii is a new entrant into commercial cultivation, hence the need to optimize factors that affect yield and biological efficiency (BE) during cultivation. Two local isolates/strains, IBK 2032 and 2033, and a commercial strain, 2600, were studied for commercial cultivation suitability. Strain 2032 reached pinning 37.3 \pm 0.9 days after inoculation, followed by $2033,43.2 \pm 1.2$, and the last 2600 was $57.4 \pm 4.8$ days. Strains 2032 , 2033, and 2600 attained the harvesting stage at $49.2 \pm 6.1,53.1 \pm 3.2$, and $68 \pm 3.4$ days, respectively, after inoculation. In fruiting body (FB) yield and BE, strain 2032 had $603.5 \pm 9.2 \mathrm{~g}$ and $47.5 \% \pm 6.6 \%$, respectively, per bag; strain 2600 gave the least yield and BE. Strains 2032 and 2033 showed individual FB weight distribution values that displayed right-sided asymmetry, with coefficients of 1.73 and 1.31 , respectively, whereas strain 2600 had a coefficient of 1.09. The cap diameter was largest in strain $2033(59.7 \mathrm{~mm})$, and the least $(46.4 \mathrm{~mm})$ was in strain 2600. Strain 2032 had the best results among all parameters measured, except for FB height. The results indicated yield, $\mathrm{BE}$, and FB morphological characteristics in the local isolates that could support longer shelf life and consumer appeal.
\end{abstract}

\section{INTRODUCTION}

Pleurotus eryngii (DC: Fr.) Quél., commonly called king oyster mushroom, has high nutritional and medicinal values and has become a highly valued species among consumers in Europe, Asia, and North America. Commercial cultivation began in Italy in the mid-1970s, and nowadays, it is increasingly cultivated in over a dozen countries worldwide [1]. The attraction to this mushroom is beyond the appearance and large size of the fruiting bodies (FBs). It has twice the amount of crude polysaccharides and fat content as Pleurotus ostreatus, a species that is the second most cultivated mushrooms globally [2]. Furthermore, bioactive substances

*Corresponding Author

Omoanghe S. Isikhuemhen, Mushroom Biology \& Fungal Biotechnology

Laboratory, North Carolina A\&T State University, Greensboro, NC.

E-mail:omon@ncat.edu from king oyster FBs have found use in functional nutrition: the addition of this mushroom's FB powder $(15 \% \mathrm{w} / \mathrm{w})$ to bread dough improved its taste [3]. Pleurotus eryngii has medicinal properties. The FB extracts of this mushroom have potent antimicrobial activity against Escherichia coli, Staphylococcus aureus, Bacillus subtilis, and Candida albicans [4]. Polysaccharides and proteins in $P$. eryngii tissues have immunomodulating and antitumor properties $[5,6]$.

At present, king oyster mushroom production's total volume is only $0.3 \%-0.5 \%$ of mushrooms grown in Ukraine. At the same time, buyers are ready to pay three times more than the equivalent amount of champignon or the common oyster mushrooms $(P$. ostreatus). In Portugal, $P$. eryngii commands high consumer preference and price compared to other cultivated mushrooms [7]. It is the same situation in Ukraine. However, the absence of adapted strains and production technologies using local raw materials can limit exotic mushrooms' mass production. When 
cultivated on locally available substrates, the strains that have a high yield and marketable features (consumer appeals) are critical for making a profit in mushroom production. Scientists are actively looking for new and promising $P$. eryngii strains with better marketable features than the existing commercially available ones [8]. Such improved and locally adapted strains are crucial because commercial mushroom production technologies and location vary greatly; strains and species most adapted to particular locations and production technologies differ. In Italy, seven commercial and five wild P. eryngii strains were evaluated for various characteristics to determine the strains most suitable for commercial cultivation [8]. In general, the size and shape of FBs are criteria farmers consider when choosing the strain to cultivate, which will give the FBs most suitable for postharvest processing (long shelf life and resilience to mechanical damage during packaging). These are critical factors for transporting and distributing the mushrooms over long distances, including export to foreign countries [8]. In a country like Ukraine, where there is the need to expand $P$. eryngii production, it is critical to have strains most adapted to cultivation on locally available substrates and the prevailing local conditions of commercial exotic mushrooms' production. Therefore, the purpose of this study was to compare the FB morphological characteristics and productivity of local isolates of P. eryngii strains IBK 2032 and 2033 with the commercial strain M 2600.

\section{MATERIALS AND METHODS}

\subsection{Origin of Cultures}

The culture of $P$. eryngii M 2600 strain was acquired from Mycelia nv. (https://www.mycelia.be/en/strain-list/m-2600-pleurotuseryngii), maintained on potato dextrose agar (PDA) media slants, and stored at $2^{\circ} \mathrm{C}-4^{\circ} \mathrm{C}$ until used. P. eryngii IBK 2032 and 2033 strains were isolated from carpophores collected in the wild in the Dnepropetrovsk and Kharkov regions of Ukraine. Strain 2032 was collected from decaying leaf litter near the base of Eryngium campestre L. and 2033 near the thicket of Ferula communis L. The strains were identified following the description of Zerova et al. [9], and deposited in the IBK Mushroom Culture Collection $[10,11]$. The cultures were activated and grown on PDA (Difco Cat\#: 213400). They were cultured onto new PDA medium plates $(90 \mathrm{~mm})$ and incubated for 10 days at $22^{\circ} \mathrm{C}-24^{\circ} \mathrm{C}$ before use to inoculate sterile grain material to obtain spawn.

\subsection{Mycelia Spawn}

Spawn was made with barley, wheat, rape, flax, and chalk $\left(\mathrm{CaCO}_{3}\right)$ combined in the ratio $60: 30: 8: 1: 1$. Precooked barley and wheat and presoaked rapeseeds, flax, and chalk were mixed and loaded into polypropylene bags of size $570 \times 470 \mathrm{~mm}$, PP75/BEU6/X4757 (https://saco2.com/shop/zipper-filter/autoclavable-pp-123c\%CB\%9A-253-f\%CB\%9A/pp75beu6x47-57/), and sterilized at $128^{\circ} \mathrm{C}$ and $1.8 \mathrm{~atm}$ for 180 minutes. Upon cooling, the sterile grain mixture was inoculated with the mother spawn $(0.5 \% \mathrm{w} / \mathrm{w})$, and sealed and incubated at $24^{\circ} \mathrm{C} \pm 1{ }^{\circ} \mathrm{C}$ for 8 days before thorough mixing to achieve uniformity. After $11 \pm 1$ days, the spawn was ready and it was stored in a refrigerator $\left(2^{\circ} \mathrm{C} \pm 1^{\circ} \mathrm{C}\right)$ until used.

\subsection{Substrates}

The cultivation substrate was composed of alder (Alnus glutinosa (L.) Gaertn) sawdust. The moisture content in the sawdust, wheat bran, and chalk was $10 \%, 7 \%$, and $5 \%$, respectively. The substrate materials (sawdust, wheat bran, and chalk) were combined in the ratio of 18:17:1, respectively, and the water content was adjusted to $65 \%$ [12]. The substrate was packed into polypropylene bags $(580 \times 490 \mathrm{~mm})$, PP75/BEU6/X47-57 (from Sac02, Belgium) The bags (average weight $3,256 \pm 18 \mathrm{~g}$ ) were sterilized at $121^{\circ} \mathrm{C} \pm$ $1{ }^{\circ} \mathrm{C}$ and 15 pounds per square inch for 120 minutes. The average weight of the substrate bags after sterilization was 3,249 $\pm 7 \mathrm{~g}$. The substrate bags were inoculated with spawn $(5 \% \mathrm{w} / \mathrm{w})$, sealed under aseptic conditions, and incubated at $24^{\circ} \mathrm{C} \pm 2{ }^{\circ} \mathrm{C}$ and relative humidity $68 \% \pm 2 \%$.

\subsection{Fruiting and Yield Characteristics}

At the initiation of fruiting, i.e., when pinheads appeared, the substrate bags were weighed again, and the weight loss in each bag was recorded. The bags were randomly distributed in a grow room with conditions set at temperature $16^{\circ} \mathrm{C} \pm 2^{\circ} \mathrm{C}$, relative humidity $95 \% \pm 3 \%$, and $\mathrm{CO}_{2} 1,250 \pm 150 \mathrm{ppm}$. At maturity, each bag was opened at the top and the bag's sides were rolled down to expose about $30 \%$ of the total surface area. In the first 5 days of fruiting, illumination was maintained at 150 lux for 8 hours per day, after which daylight (not more than 40 lux) was sufficient until harvest. Data for the following parameters were collected: 1 . the number of days from inoculation to pinning, 2. the number of days from inoculation to harvest, 3 . the total weight of FBs from each bag, and 4. basidiocarp morphological indexes (BMI) for each mushroom [weight $(\mathrm{g})$, height $(\mathrm{mm})$, stipe diameter $(\mathrm{mm})$, and cap diameter (mm)]. BMI was measured with 25 FBs (five FBs collected from five random bags) and was measured for each strain during each repeat experiment ( 75 total FBs in the three repeat experiments). The biological efficacy (BE) was calculated using the following formula: the weight of freshly picked mushrooms/substrate weight (dry matter) 100\% [12].

\subsection{Substrate Analysis}

Since the experiment was repeated over three seasons, the substrates were analyzed. Moisture content in the substrate was determined as the difference in weight after drying a $10 \mathrm{~g}$ quantity of the substrate to constant weight at $102^{\circ} \mathrm{C} \pm 2{ }^{\circ} \mathrm{C}$ (usually $6-8$ hours). The ash content was determined by weighing $3 \mathrm{~g}$ of dry milled substrate material into ceramic crucibles of known weights and put in the oven $\left(550^{\circ} \mathrm{C} \pm 10^{\circ} \mathrm{C}\right)$ for 3 hours and cooled in a desiccator. The leftover material in the crucible was weighed to obtain ash content [13]. Total nitrogen was determined by the Kjeldahl method [14]. The $C / N$ ratio was determined with the formula $C / N=0.52(100-a) / N$, where $a$ is ash content $(\%), 0.52$ is carbon content coefficient $[15,16]$, and $N$ is total nitrogen content $(\%)$.

Statistical analysis on the data obtained was carried out on the above parameters with Microsoft Office Excel 2016 MSO (16.0.4266.1001) kod 00339-10000-00000-AA963 and QI Macros superstructure. Statistics on BMI were evaluated with STATISTICA 13. 


\section{RESULTS AND DISCUSSION}

\subsection{Substrate Composition}

The substrate analysis data from the three repeat tests did not show significant differences in the parameters of moisture contents (Table 1).

Wheat bran-supplemented sawdust substrate was used for this study to compare our results with reports in the literature about the cultivation of $P$. eryngii (Wanzenbock et al., 2017). The substrate compositions in different seasons had a $C / N$ ratio in the range 45 47, which is optimum for $P$. eryngii cultivation [17]. Philippoussis et al. [18] noted a positive correlation $\left(r^{2}=0.98\right)$ between the $C / N$ ratio (within the range of 32.7-59.3) and mushroom yield in $P$. eryngii. The $C / N$ ratio of $46.86 \pm 1.11$ found in our substrate is suitable for the cultivation of other Pleurotus species on sawdust substrate $[18,19]$.

\subsection{Colonization and Mushroom FB Development}

The fastest strain (2032) reached pinning $37.3 \pm 0.9$ days after inoculation, followed by $2033(43.2 \pm 1.2)$, and the last was 2600 (57.4 \pm 4.8 days). Strains 2032, 2033, and 2600 reached the harvesting stage $49.2 \pm 6.1,53.1 \pm 3.2$, and $68 \pm 3.4$ days after inoculation, respectively (Fig. 1).

Single-factor statistical analysis (ANOVA) on the number of days to reach pinning and first harvest indicated no significant difference within the repeat cultivation in each strain, but a significant difference between the three strains tested $(p<0.01)$. Moonmoon et al. [20] used sawdust substrate and reported 27-30 and 39-52 days to pinning and harvest, respectively, during the cultivation of P. eryngii. However, their substrate composition (sawdust, wheat bran, and rice husk) and the strains were different from those used in our experiment. Szarvas and Gyorfi [21] grew P. eryngii isolates using the substrate from birch sawdust supplemented with wheat bran and soybean, and they reported about 60 days to attain the harvesting stage.

\subsection{Yield and BE}

In general, the maximum average total FB yield from each bag was $565.9 \pm 12.3 \mathrm{~g}$ in strain 2032, and the least was $312.2 \pm 7.8$ $\mathrm{g}$ in strain 2600 (Table 2). The FB yield in each strain during the three seasons of cultivation indicated slight variations that were not significantly different $(p>0.05)$, except in the Oct-Dec 2018 cultivation in strain 2032. The FB yield, which was $603.5 \pm 9.2$, was significantly different from $568.4 \pm 12.6$ and $525.8 \pm 15.2$ obtained during the Feb-Apr 2018 and Jan-March 2019 cultivation seasons, respectively, in strain 2032. However, statistical analyses indicate significant differences $(p=0.02)$ in total FB yield among the three strains tested during each season (Table 2).

Similarly, statistical analyses (ANOVA) on BE values indicated significant differences between strains $(p=0.04)$. The highest BE was in strain $2032(47.5 \% \pm 6.6 \%)$, followed by strain 2033 $(32.7 \% \pm 3.9 \%)$, and the least was in $2600(25.1 \% \pm 3.2 \%)$. The BE

Table 1: Chemical and physical properties of substrate used in different seasons.

\begin{tabular}{lcccccc} 
Parameters & $\begin{array}{c}\text { Mean } \pm \\
\text { standard error }\end{array}$ & Feb-Apr 2018 & Oct-Dec 2018 & Jan-Mar 2019 & LCD $_{\mathbf{0 . 0 5}}$ & $\boldsymbol{p}$ value \\
Moisture content (\%) & $63.73 \pm 0.56$ & $63.67 \pm 0.27$ & $65.13 \pm 0.49$ & $62.4 \pm 1.31$ & 2.84 & 0.14 \\
$\mathrm{pH}$ & $6.42 \pm 0.05$ & $6.43 \pm 0.13$ & $6.4 \pm 0.05$ & $6.43 \pm 0.12$ & 0.38 & 0.97 \\
Nitrogen total (\%) & $1.08 \pm 0.03$ & $1.09 \pm 0.07$ & $1.06 \pm 0.02$ & $1.10 \pm 0.06$ & 0.19 & 0.13 \\
Ash (\%) & $2.43 \pm 0.08$ & $2.39 \pm 0.03$ & $2.54 \pm 0.24$ & $2.35 \pm 0.08$ & 0.51 & 0.66 \\
C/N ratio & $46.86 \pm 1.11$ & $46.17 \pm 2.53$ & $47.83 \pm 0.79$ & $45.59 \pm 2.62$ & 7.45 & 0.85 \\
\hline
\end{tabular}

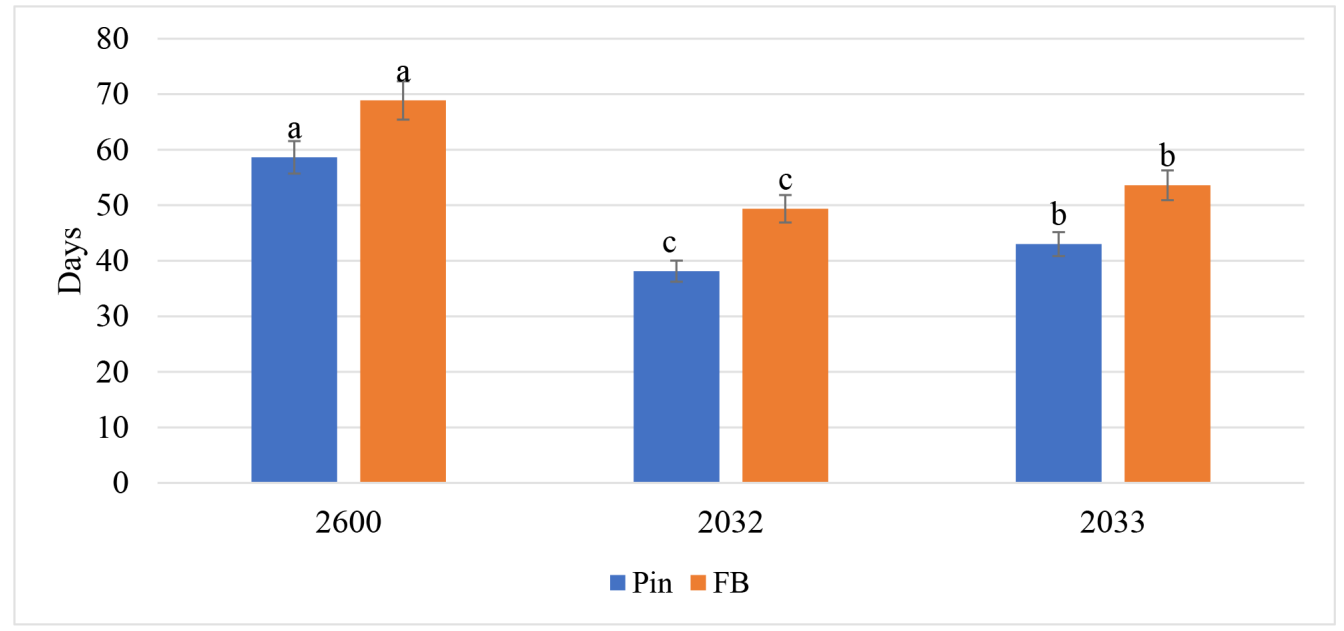

Figure 1: Time to primordia/pinning and FB development in P. eryngii. 
Table 2: Average FB yield ( $\mathrm{g} / \mathrm{bag} \pm$ standard error) from three seasons of cultivation of $P$. eryngii.

\begin{tabular}{|c|c|c|c|c|c|}
\hline \multirow{3}{*}{ Strains } & \multirow{3}{*}{$\begin{array}{l}\text { Mean weight of bag } \\
\text { after inoculation }\end{array}$} & \multicolumn{3}{|c|}{ Mean FB yield in different seasons } & \multirow{3}{*}{$\mathbf{L S D}_{0.05}$} \\
\hline & & Feb-Apr & Oct-Dec & & \\
\hline & & 2018 & 2018 & 2019 & \\
\hline 2600 & $3,412 \pm 6$ & $289.6^{c} \pm 16.0$ & $297.4^{\mathrm{c}} \pm 4.3$ & $312.2^{\mathrm{c}} \pm 7.8$ & 30.8 \\
\hline 2032 & $3,414 \pm 6$ & $568.4^{\mathrm{a}} \pm 12.6$ & $603.5^{\mathrm{a}} \pm 9.2$ & $525.8^{\mathrm{a}} \pm 15.2$ & 37.3 \\
\hline 2033 & $3,408 \pm 4$ & $396.2^{\mathrm{b}} \pm 10.3$ & $396.2^{\mathrm{b}} \pm 5.1$ & $387.9^{\mathrm{b}} \pm 10.4$ & 23.7 \\
\hline $\mathrm{LSD}_{0.05}$ & & 31.76 & 30.76 & 29.70 & \\
\hline
\end{tabular}

Mean values with different letters in each column are significantly $(p<0.05)$ different.

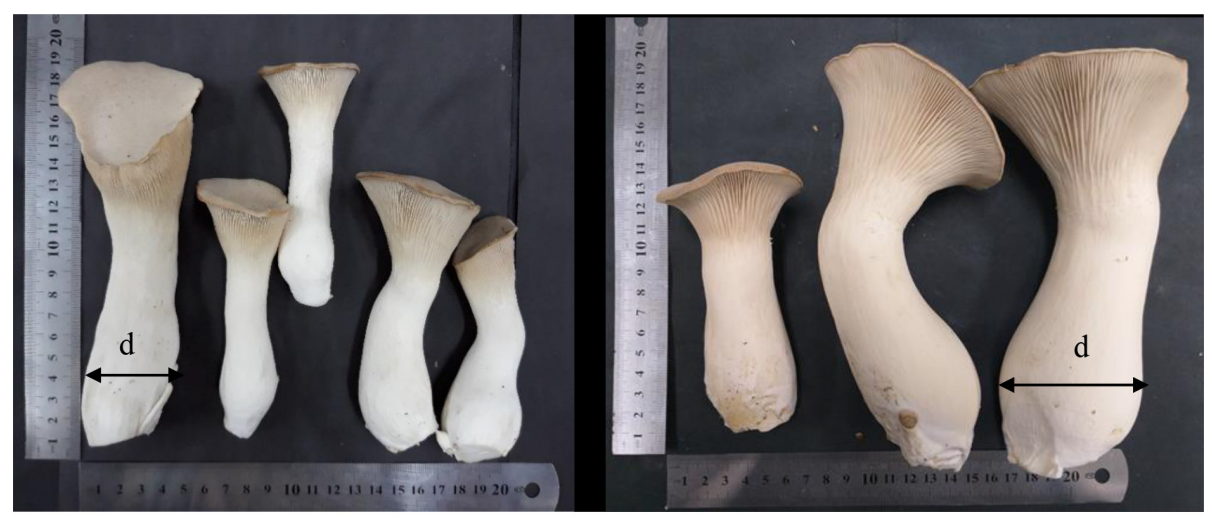

a

$\mathbf{B}$

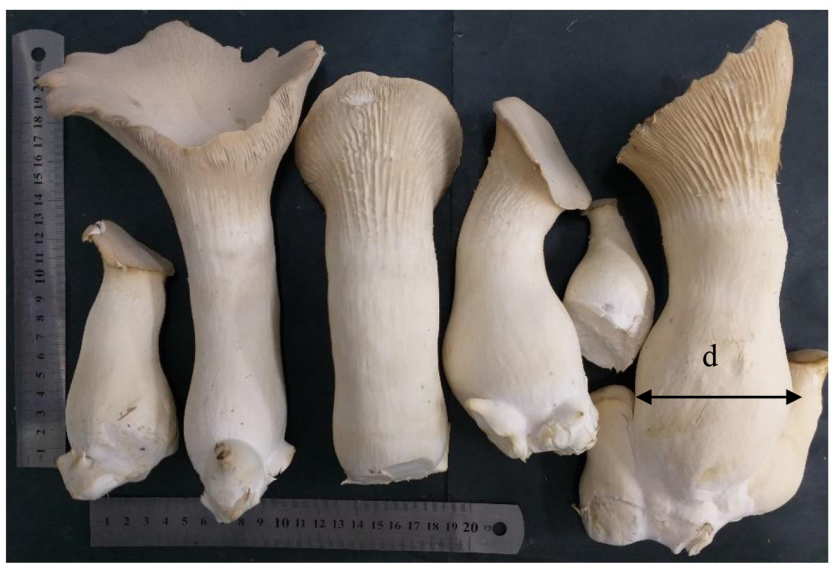

Figure 2: Shapes of FBs from different strains of P. eryngii: a) strain 2600, b) strain 2033, c) strain 2032, and d) FB diameter.

values for 2032 and 2033 were $25 \%$ and $5 \%$ higher than strain 2600 in this experiment, respectively. The $\mathrm{BE}$ in all the strains tested were higher than the 20.3 BE reported by Wanzenbock et al. The BE of 2032 and 2033 strains was similar to the report of Sardar et al. [22], who obtained BE values of $35.47 \pm 0.76$ when $P$. eryngii was cultivated on a substrate containing sawdust, rice, and wheat straw. The results from strains 2032 and 2033 were lower than those reported by Xie et al. [23], who used different agriculture wastes to obtain BE as high as $36.8 \%$ and $52.4 \%$. Nevertheless, higher yield and BE from local isolates 2032 and 2033 could be due to these isolates' unique genetic backgrounds. Furthermore, evolution/adaptation to prevailing ecogeographic conditions in
Ukraine could be responsible for the superior performance of strains 2032 and 2033.

\subsection{Morphological Characteristics}

Representative FBs from strains 2600, 2033, and 2032 are shown in Figure 2a, b, and c, respectively. The morphological parameters of FB weight, height, stipe, and cap diameter that were measured indicated significant differences in test strains' FBs (Table 3).

Seventy-five FBs were collected per strain and analyzed for variations in individual FB weight. In strain 2600, 54 out of 75 FBs had weights that ranged between 25 and 45 g, indicating a 
Table 3: Morphological characteristics in FBs ( \pm standard error) of P. eryngii.

\begin{tabular}{ccccc} 
Strain & Weight $(\mathbf{g})$ & Height $(\mathbf{m m})$ & Stem diameter $(\mathbf{m m})$ & Cap diameter $(\mathbf{m m})$ \\
2600 & $39.0^{\mathrm{b}} \pm 2.3$ & $77.9^{\mathrm{a}} \pm 1.9$ & $28.2^{\mathrm{b}} \pm 0.7$ & $46.4^{\mathrm{b}} \pm 1.4$ \\
2032 & $61.3^{\mathrm{a}} \pm 4.8$ & $63.9^{\mathrm{b}} \pm 1.4$ & $34.6^{\mathrm{a}} \pm 1.1$ & $57.9^{\mathrm{a}} \pm 1.2$ \\
2033 & $58.6^{\mathrm{a}} \pm 4.2$ & $66.8^{\mathrm{b}} \pm 1.6$ & $32.1^{\mathrm{a}} \pm 0.9$ & $59.7^{\mathrm{a}} \pm 2.0$ \\
$\mathrm{LSD}_{0.05}$ & 10.9 & 4.6 & 2.6 & 4.4 \\
\hline
\end{tabular}

Values with different letters in each column are significantly $(p<0.05)$ different.

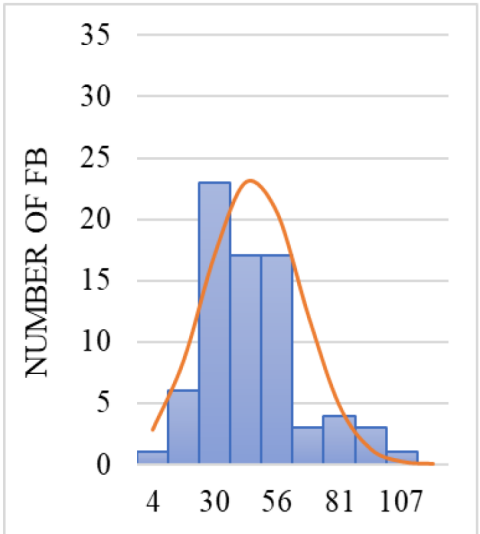

$\begin{array}{lllll}4 & 30 & 56 & 81 & 107\end{array}$
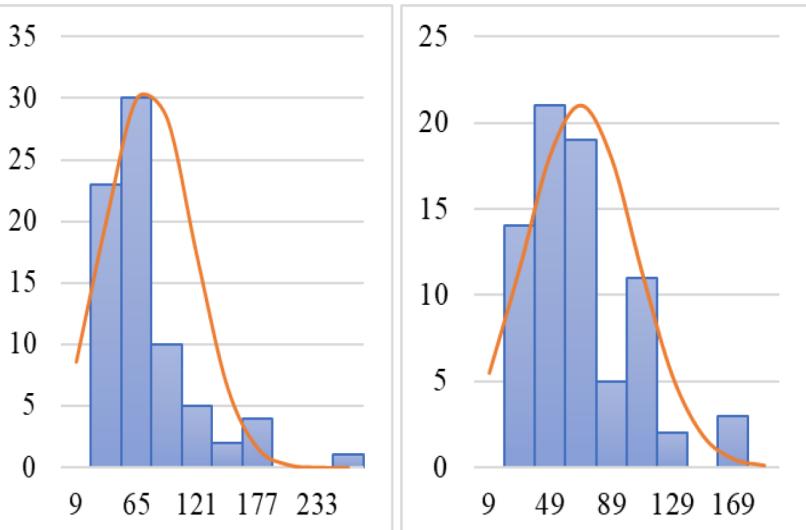

\section{FB mass (g)}

M 2600

IBK 2032

IBK 2033

Figure 3: Variations and distribution of FB weight (g) among P. eryngii strains.

tight peak shown in Figure 3. However, strains 2032 and 2033 gave FBs with higher weights and a wider spread of FB weight across the spectrum. For strains 2032 and 2033, the distribution of values in samples had significant right-sided asymmetry, and descriptive statistical analysis indicated coefficients of 1.73 and 1.31 , respectively. The estimation of FBs' weight in strain 2600 showed the smallest dispersion of results from average and a lower sample asymmetry coefficient of 1.09.

The average height of FBs in strain 2600 was 11 and $14 \mathrm{~mm}$ higher than results from strains 2032 and 2033, respectively (Fig. 4). The maximum FB height was $127 \mathrm{~mm}$ in strain 2600, the minimum was $40 \mathrm{~mm}$ in strain 2033, and the FBs from strains 2032 and 2033 did not exceed $100 \mathrm{~mm}$. The samples' distribution based on FBs' height was more uniform and indicated that the asymmetry coefficient did not exceed 0.3 in strains 2032 and 2600; it was below 0.2 in strain 2033 .

The largest FB cap diameter $(59.7 \pm 2.0 \mathrm{~mm})$ was in 2033 , and the least $(46.4 \pm 1.4 \mathrm{~mm})$ was in strain 2600 . The highest variation in pileus diameter was found in strain 2033, ranging from 22 to 115 $\mathrm{mm}$. The least cap diameter variations were between 22 and $75 \mathrm{~mm}$ in strain 2600 (Fig. 5). Most of the FBs of strains 2032 and 2033 had a cap diameter within the range of 45-65 $\mathrm{mm}$, while those of strain 2600 were within a 30-50 $\mathrm{mm}$ diameter. The average FB cap diameter of strain 2600 was 12 and $13 \mathrm{~mm}$ less than those of strains 2032 and 2033. The cap diameter range values in strain 2600 were significantly $(p<0.01)$ different from those in strains 2032 and 2033. The range of variations in cap diameter in all strains tested is in line with the earlier report of Ha et al. [24], who recorded a 59-64.9 mm diameter in the cultivation of $P$. eryngii. Strain 2032 had the least stipe diameter $(15 \mathrm{~mm})$ and the highest was $61 \mathrm{~mm}$. The stipe diameter of FBs from strain 2600 was from 18 to $50 \mathrm{~mm}$ and was on average 4 and $6 \mathrm{~mm}$ less than FBs from strains 2032 and 2033, respectively (Fig. 6). Strains 2600, 2032, and 2033 have morphological characteristics comparable to earlier reports of stipe diameters $27-32 \mathrm{~mm}$ and cap diameter 53-82 $\mathrm{mm}$ [20]. However, the variations in FB morphological parameters during three repeat cultivations could account for the predictability of occurrence in mushrooms' morphological features in terms of weight, height, cap, and stipe, which are very important in commercial cultivation.

The analysis of the FBs' morphological parameters determined that commercial strain 2600 had significant differences in all morphological characteristics, FB weight and height, cap, and stipe diameter $(p<0.01)$, in comparison to local isolates IBK 2032 and 2033. The FBs of strain 2600 had an elongated cylindrical shape compared to the FBs from isolates 2032 and 2033, which showed substantially larger stipe diameters toward the base of the FB. 


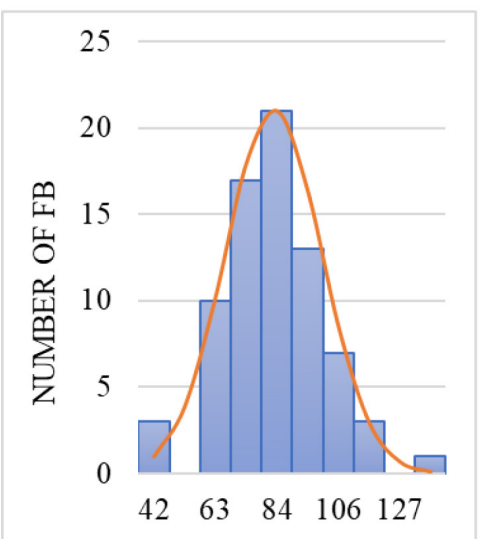

M 2600

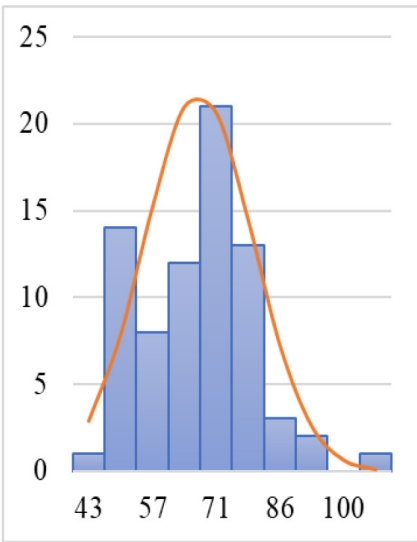

Height of FB (mm)

IBK 2032

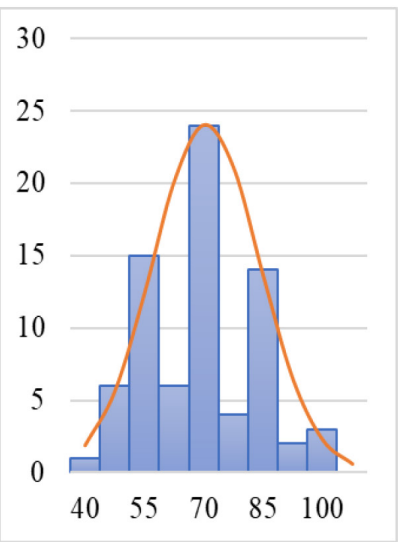

IBK 2033

Figure 4: Variations and distribution of FB height (mm) among P. eryngii strains.

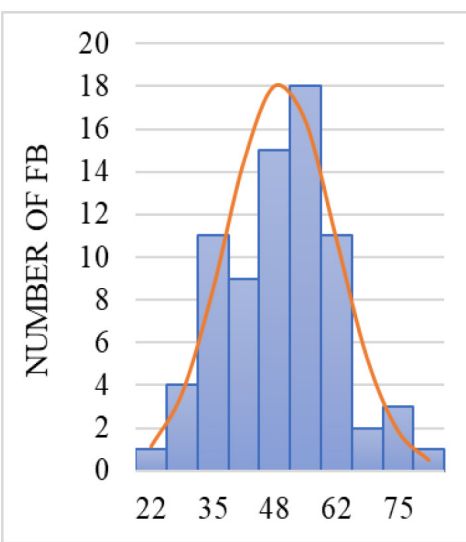

M 2600

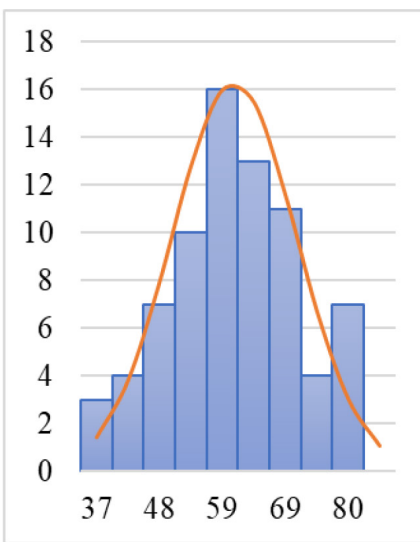

Cap diameter $(\mathbf{m m})$

IBK 2032

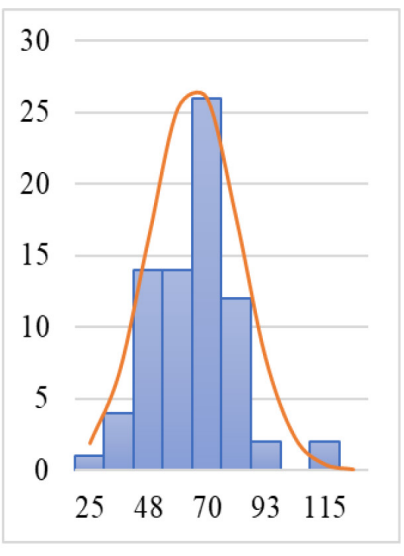

IBK 2033

Figure 5: Variations and distribution of FB cap diameter (mm) among P. eryngii strains.

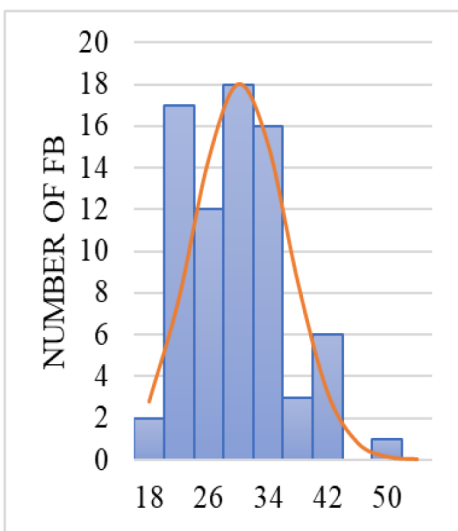

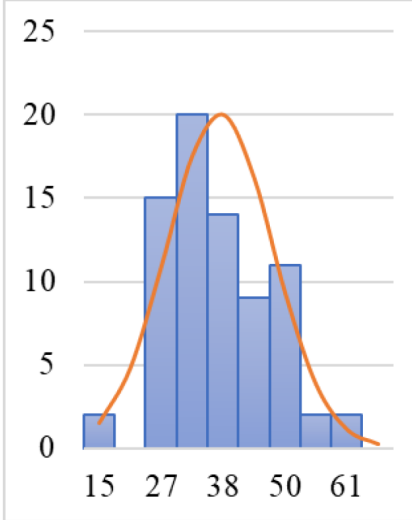

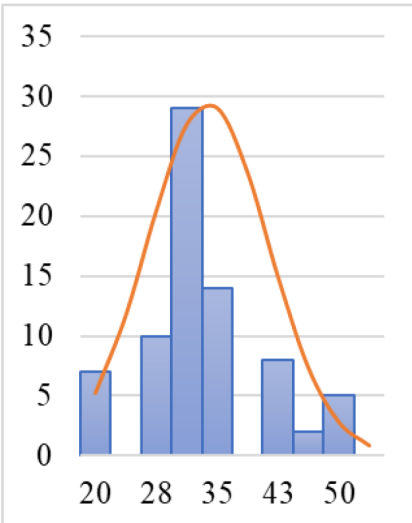

Stipe diameter (mm)

IBK 2033

Figure 6: Variations and distribution of FB stipe diameter $(\mathrm{mm})$ among strains of P. eryngii. 
In the morphological characteristics studied, most samples from strains 2032 and 2033 had similar features and characteristics that were, in most cases, different from 2600 . About $48 \%$ of individual FB weight was between 40 and $80 \mathrm{~g}, 64 \%$ individual FB from both strains had height between 50 and $70 \mathrm{~mm}, 55 \%$ (2032) and $72 \%$ (2033) had a cap diameter between 50 and $70 \mathrm{~mm}$, and $82 \%$ (2032) and 64\% (2033) had a stipe diameter between 20 and $40 \mathrm{~mm}$. In M $2600,58 \%$ FB weighed between 20 and $60 \mathrm{~g}, 40 \%$ between 70 and $90 \mathrm{~mm}$ in height, $67 \%$ between 20 and $40 \mathrm{~mm}$ in cap diameter, and $50 \%$ between 40 and $60 \mathrm{~mm}$ in stipe diameter. Figs. 3-6 represent low dispersion from average values obtained. The fact that the same substrate was used for cultivation and the fruiting was carried out in the same climate-controlled environment may indicate that the differences between 2600 and the two local strains, 2032 and 2033, are most likely due to inherent genetic traits in the strains tested. This line of thought is supported further by the fact that strains 2032 and 2033 that were collected from the same locality showed no difference in most characteristics studied.

The results obtained from morphological studies could be useful for designing the package's size to reduce mechanical damage to the delicate FB of the $P$. eryngii mushrooms from strains 2032 and 2033 under commercial cultivation. Such an approach will help to increase the shelf life of mushrooms when they are sold fresh. Furthermore, the wide variation in FB morphological characteristics of strains 2032 and 2033 suggests that making different FB size products, e.g., small, medium, and large FB packages, would benefit marketers of consumer mushroom products.

\section{CONCLUSION}

This study indicated that the two local isolates IBK 2032 and 2033 outperformed the commercial strain 2600 in all parameters measured, except FB height. The time to first flush harvest in strains 2032 (49) and 2033 (53) was significantly lower than the commercial strain 2600 (68 days). Similarly, BE values in strains $2032(47.5 \%)$ and $2033(32.7 \%)$ were significantly higher ( $p=$ $0.035)$ than in strain $2600(25.1 \%)$. Commercial production could exploit the higher variations in FB morphology in strains 2032 and 2033 to generate different consumer products from FBs. Further studies on strains 2032 and 2033 regarding their performance in large-scale production, optimization of substrates' composition, and growth condition to achieve higher yield are recommended.

\section{REF ERENCES}

1. Stajic M, Vukojevic J, Duletic'-Lauševic S. Biology of Pleurotus eryngii and role in biotechnological processes: a review. Crit Rev Biotechnol 2009;29:55-66. doi:10.1080/07388550802688821

2. Krüzselyi D, Kovács D, Vetter J. Chemical analysis of king oyster mushroom (Pleurotus eryngii) fruitbodies. Acta Aliment 2016;45:207. doi:10.1556/066.2016.45.1.3

3. Biao Y, Chen X, Wang S, Chen G, Mcclements DJ, Zhao L. Impact of mushroom (Pleurotus eryngii) flour upon quality attributes of wheat dough and functional cookies-baked products. Food Sci Nutr 2020;8:361-70. doi:10.1002/fsn3.1315

4. Acay H, Yildirim A, Güzel EE, Kaya N, Baran MF. Evaluation and characterization of Pleurotus eryngii extract-loaded chitosan nanoparticles as antimicrobial agents against some human pathogens. Prep Biochem Biotechnol 2020;50:897-906. doi:10.1080/10826068.2 020.1765376
5. Kim YH, Jung EG, Han KI, Patnaik BB, Kwon HJ, Lee HS, et al. Immunomodulatory effects of extracellular $\beta$-glucan isolated from the king oyster mushroom Pleurotus eryngii (Agaricomycetes) and its sulfated form on signaling molecules involved in innate immunity. Int J Med Mushrooms 2017;19:521-33. doi:10.1615/IntJMedMushrooms. v19.i6.40

6. Vetvicka V, Gover O, Hayby H, Danay O, Ezov N, Hadar Y, et al. Immunomodulating effects exerted by glucans extracted from the king oyster culinary-medicinal mushroom Pleurotus eryngii (Agaricomycetes) grown in substrates containing various concentrations of olive mill waste. Int J Med Mushrooms 2019;21:8191. doi:110.1615/intjmedmushrooms.2019031549

7. Boin EASF, Azevedo CMAM, Nunes JMSA, Guerra MM. Consumer acceptability and descriptive characterization of fresh and dried king oyster (Pleurotus eryngii) and hedgehog (Hydnum repandum) mushrooms. J Food Res 2016;5:55-64. doi:10.5539/jfr.v5n4p55

8. Castronuovo D, Mang SM, Becce A, Candido V, Cardone L, Camele I. Morphological and productivity comparison between commercial and wild isolates of Pleurotus eryngii (DC: Fr.) Quél. Ital J Agron 2019;14:170-5. doi:10.4081/ija.2019.1458

9. Zerova MY, Sosi `n PY, Rozhenko G. Determinant of Ukrainian mushrooms. Naukova Dumka, Kyiv, Ukraine, 1979.

10. Lomberg ML, Mikhailova OB, Bisko NA. Mushroom culture collection IBK as a subject of national heritage of Ukraine. Ukr Bot 2015;72:22-8. doi:10.15407/ukrbotj72.01.022

11. Bisko NA, Lomberg ML, Mykchaylova OB, Mytropolska NY. Conservation of biotechnological important species diversity and genetic resource of rare and endangered fungi of Ukraine. Ukr Bot 2018;1:18-27. doi:10.29228/plantfungalres.41

12. Chang ST, Hayes WA. The biology and cultivation of edible mushrooms. New York Academic Press, New York, NY, 1978.

13. Toscano G, Riva G, Foppa Pedretti E, Corinaldesi F, Mengarelli C, Duca D. Investigation on wood pellet quality and relationship between ash content and the most important chemical elements. Biomass Bioenerg 2013;56:317-22. doi:10.1016/j.biombioe.2013.05.012

14. Nelson DW, Sommers LE. Determination of total nitrogen in plant material 1. J Agron 1973;65:109-12. doi:10.2134/agronj1973.000219 62006500010033x

15. Lamlom SH, Savidge RA. A reassessment of carbon content in wood: variation within and between 41 North American species. Biomass Bioenerg 2003;25:381-8. doi:10.1016/s0961-9534(03)00033-3

16. Mokrzycki J, Gazińska M, Fedyna M, Karcz R, Lorenc-Grabowska E, Rutkowski P. Pyrolysis and torrefaction of waste wood chips and cone-like flowers derived from black alder (Alnus glutinosa $\mathrm{L}$. Gaertn.) for sustainable solid fuel production. Biomass Bioenerg 2020;143:105842. doi:10.1016/j.biombioe.2020.105842

17. Wanzenböck E, Apprich S, Tirpanalan Ö, Zitz U, Kracher D, Schedle $\mathrm{K}$, et al. Wheat bran biodegradation by edible Pleurotus fungi- a sustainable perspective for food and feed. LWT 2017;86:123-31; doi:10.1016/j.lwt.2017.07.051

18. Philippoussis A, Zervakis G, Diamantopoulou P. Bioconversion of agricultural lignocellulosic wastes through the cultivation of the edible mushrooms Agrocybe aegerita, Volvariella volvacea and Pleurotus spp. World J Microbiol Biotechnol 2001;17:191-200. doi:10.1023/A:1016685530312

19. Oh T, Lee YH, Kim CH, Cho YK, Jang MJ. Comparative study of the growth characteristics of Pleurotus eryngii by using alternative substrates to rice bran. J Mushrooms 2017;15:57-60. doi:10.14480/ JM.2017.15.1.57

20. Moonmoon M, Uddin MN, Ahmed S, Shelly NJ, Khan MA Cultivation of different strains of king oyster mushroom (Pleurotus eryngii) on sawdust and rice straw in Bangladesh. Saudi J Biol Sci 2010;17:341-5. doi:10.1016/j.sjbs.2010.05.004

21. Szarvas J, Győrfi J. Comparative cultivation experiments of king oyster mushroom (Pleurotus eryngii) isolates. Kertgazdasag 2011;43:3-14. doi:10.1556/AAlim.40.2011.Suppl.20 
23. Sardar H, Ali MA, Anjum MA, Nawaz F, Hussain S, Naz S, et al. Agro-industrial residues influence mineral elements accumulation and nutritional composition of king oyster mushroom (Pleurotus eryngii). Sci Hortic 2017;225:327-34. doi:10.1016/j.scienta.2017.07.010

24. Xie C, Yan L, Gong W, Zhu Z, Tan S, Chen D, et al. Effects of different substrates on lignocellulosic enzyme expression, enzyme activity, substrate utilization and biological efficiency of Pleurotus eryngii. Cell Physiol Biochem 2016;39:1479-94. doi:10.1159/000447851

25. Ha TM, Ju YC, Jeon DH, Choi JI, Lee TS. Characteristics and breeding of a new variety Pleurotus eryngii, Gongi No. 3. J Mushrooms 2011;9:22-6. doi:10.14480/JM.2011.9.1.022

\section{How to cite this article:}

Bandura I, Isikhuemhen OS, Kulik A, Bisko N, Serduik $\mathrm{M}$, Khareba V, et al. Mushroom fruiting body yield and morphological characteristics from different strains of Pleurotus eryngii. J Appl Biol Biotech 2022; 10(01):1-8. 